\title{
Transferências e receitas do sistema único de saúde durante a covid- 19 nos municípios de Pernambuco
}

As tecnologias da informação e comunicação - TICs, com o uso da internet tem transformado as relações sociais e o desenvolvimento da sociedade. Essas mudanças refletem na gestão pública que também tem procurado inovar, mudando a relação entre governo, Estado e sociedade. Os gestores públicos precisam desenvolver uma gestão participativa, descentralizada e transparente, disponibilizando o conhecimento de dados abertos no intuito de ampliar a inclusão e controle social. 0 objetivo geral deste estudo foi avaliar se as informações dos portais da transparência de 32 municípios pernambucanos estão em conformidade com a lei da transparência (LC 131/2009), no que se refere transferências e receitas do SUS para o enfrentamento ao coronavírus COVID-19. Através da pesquisa descritiva fo feito levantamento das informações, disponibilizadas pelos portais da transparência das prefeituras avaliadas e do portal do Fundo Nacional de Saúde. A análise dos dados demonstra que os gestores de alguns municípios não estão cumprindo as atribuições previstas legalmente para uma gestão responsável e transparente, dificultando a accountability social.

Palavras-chave: TICs; Gestão pública; Portal da Transparência; Accountability; COVID-19.

\section{Transfers and revenues from the unified health system during the covid-19 in the municipalities of Pernambuco}

\begin{abstract}
Information and communication technologies - ICTs, with the use of the internet, have transformed social relations and the development of society. These changes reflect the public management that has also sought to innovate, changing the relationship between government, state and society. Public managers need to develop participative, decentralized and transparent management, making available open data knowledge in order to expand social inclusion and control. The general objective of this study was to assess whether the information from the transparency portals of 32 municipalities in Pernambuco are in compliance with the transparency law (LC 131/2009), regarding SUS transfers and revenues for coping with the coronavirus COVID-19. Through the descriptive research, a survey of the information was made available through the transparency portals of the evaluated municipalities and the National Health Fund portal. The analysis of the data shows that the managers of some municipalities are not fulfilling the attributions legally provided for responsible management and transparent, hampering social accountability.
\end{abstract}

Keywords: ICTs; Public Management; Transparency Portal; Accountability; COVID-19.

Topic: Gestão Pública

Reviewed anonymously in the process of blind peer.
Received: $11 / 05 / 2020$

Approved: 22/08/2020
Maria Cristiane Pereira dos Santos (iD) Universidade Federal de Pernambuco, Brasil http://lattes.cnpq.br/5504286706540347 http://orcid.org/0000-0002-9732-7004 mariacristiane.santos@ufpe.br

Elizabeth Alves dos Santos (iD)

Universidade Federal de Pernambuco, Brasil http://lattes.cnpq.br/3513140424942323 http://orcid.org/0000-0003-4864-1774 elizabeth.santos@ufpe.br
Referencing this:

SANTOS, M. C. P.; SANTOS, E. A.. Transferências e receitas do sistema único de saúde durante a covid-19 nos municípios de Pernambuco. Management Journal, v.2, n.2, p.10-25, 2020. DOI: http://doi.org/10.6008/CBPC2674-6417.2020.002.0002 


\section{INTRODUÇÃO}

A sociedade atual é marcada pelas rápidas e constantes transformações, em que o uso da internet tem sido um fator determinante para novas configurações das relações sociais e desenvolvimento da sociedade, as barreiras de tempo e espaço foram superadas através do uso das Tecnologias da informação e comunicação (TICs). Do ponto de vista de Castells (1999) "tanto o espaço quanto o tempo estão sendo transformados sob o efeito combinado do paradigma da tecnologia da informação e das formas e processos sociais induzidos pelo atual processo de transformação histórica".

Nesse contexto surgem novas exigências para atuação dos governos, afim de atender as demandas da sociedade, onde a informação desempenha um papel fundamental e o uso da internet como instrumento pode viabilizar a participação cidadã. A sociedade civil de acordo com Resch et al. (2017) demanda por melhorias na prestação de serviços como os de saúde, educação, segurança e mobilidade, isso requer um comportamento ético dos gestores públicos. As reivindicações da sociedade para com a administração pública, neste sentido estão relacionadas a responsabilização e prestação de contas pelos gestores públicos, juntamente com o controle social, temas essenciais no conceito de accountability.

Diante disso, "espera-se que na sociedade da informação, pelo fato de a informação ser amplamente distribuída e os fluxos de informação não poderem mais ser controlados a partir do centro, a democracia seja fortalecida" (AKUTSU et al., 2002). Nessa perspectiva a sociedade é construída a partir dos fluxos diversos, como exemplo os fluxos de informações, tecnologia, imagens, interação organizacional, e esses fluxos expressam processos que comandam nossa vida econômica, política e simbólica (CASTELLS, 1999). Nessa sociedade as informações e dados além de estarem disponíveis na internet, possuem outro aspecto que é a produção e compartilhamento dessas informações numa interligação que independe da localização espaçotemporal das pessoas.

Um gestor público, por exemplo, independente do exercício de seu governo ser em um pequeno município ou numa grande metrópole, pode publicizar seus projetos, ações ou prestações de contas para os eleitores da sua cidade fiscalizarem através do ambiente virtual, onde essas informações podem ser verificadas por todos, independentemente do bairro ou cidade em que residem. Não é necessário o deslocamento geográfico para ir em busca do seu direito de acesso à informação, garantido na legislação brasileira. Pode existir nesse contexto uma produção e troca informação de forma descentralizada e interconectada.

A tecnologia da informação de acordo com Camilo et al. (2019) tem possibilitado a gestão pública disponibilizar o conhecimento de dados abertos, ampliando maneiras de inclusão e controle social, onde um fator relevante é a transparência como elemento essencial na administração pública. Nessa perspectiva, este estudo objetiva avaliar se as informações dos portais da transparência de 32 municípios pernambucanos estão em conformidade com a lei da transparência (LC 131/2009), no que se refere Transferências e Receitas de recursos financeiros do Sistema Único de Saúde-SUS para o enfrentamento ao coronavírus COVID-19 (BRASIL, 2009). 
As inovações tecnológicas de acordo com Balbe (2010) tem alterado a relação dos governos com os cidadãos, e a administração pública contemporânea tem reconhecido essas mudanças e adotado soluções inovadoras, essas novas práticas em grande parte estão associadas ao governo eletrônico. Assim o mundo contemporâneo exige mais dos governos, em questões como eficiência, transparência e efetividade das políticas públicas.

As questões ligadas a transparência estão diretamente relacionadas as políticas públicas, como no caso do Sistema Único de Saúde (SUS) que busca atender as necessidades de serviços de saúde de toda população. Apesar dos grandes avanços na sua implementação e consolidação, o SUS vem enfrentando uma situação precária, com insuficiência no número de leitos tanto de enfermarias quanto de UTI, falta ou insuficiência de equipamentos hospitalares, profissionais, exame laboratoriais ou medicamentos. Esse cenário foi intensificado quando surgiu a COVID-19 uma pandemia global, que teve como consequência uma elevada demanda pelos serviços de assistência médico-hospitalar, principalmente nos níveis de alta complexidade referente a disponibilidade de leitos de UTI.

Diante contexto marcado por uma situação de emergência de saúde pública, decorrente da pandemia Covid-19, no entanto caracterizado por inovações e transformações tecnológicas trazidas pelas TICs que refletem na gestão pública, requerendo dos gestores fortalecimento do controle social e uma gestão participativa, em que as pessoas possam acompanhar com clareza e transparência os gastos e investimentos públicos, a fim de uma boa governabilidade e efetividade das políticas públicas surge a questão: É possivel verificar através do portal da Transparência dos municípios e da União informações relativas as verbas do SUS destinadas ao combate a COVID 19?

\section{REVISÃO TEÓRICA}

\section{Sociedade interconectada}

O uso das tecnologias junto as modernas técnicas de administração modificaram o cenário mundial, causando transformações nas empresas e governos. Com o uso da internet governo e cidadãos podem encontrar a oportunidade para que o governo crie serviços de melhor qualidade, possibilitando a sociedade uma participação efetiva na gestão governamental (AKUTSU et al., 2002).

De acordo com Castells (1999) "os principais processos dominantes em nossa sociedade são articulados em rede, que liga os lugares diferentes e atribuem a cada um deles um papel e um peso em uma hierarquia de geração de riquezas, processamento de informação e poder, fazendo que isso, em última análise, condicione o destino de cada local". Assim Ivar (2014) esclarece que ao contrário modelo de transmissão unilateral, característico de mídias de massa, as redes de informação caracterizam-se pela ascensão de cada pessoa a um retículo que recebe, mas também produz e transmite informações aos demais.

Para Fontes (2012) com a implicação entre o local e o global, entre microprocessos e os estudos macrossociológicos, torna-se necessário estudar o poder local para explicar fenômenos políticos de alcance mais geral. As antigas formas de explicar as estruturas político-administrativas não conseguem explicar os 
complexos fluxos que incorporam novos atores, que também redefinem a relação entre sociedade, estado e esfera pública a partir da internet.

Diante desse processo são demandadas novas formas de pensar a gestão e a participação. A administração pública não pode ficar alheia as novas configurações em redes, onde são criados espaços de interação, discussões e colaboração que acontecem nos ciberespaços. Franco et al. (2019) consideram o ciberespaço como espaço do saber, caracterizado pelo compartilhamento, cooperação e construção de informações e conhecimento.

Uma importante questão dessa nova ordem social de acordo com Fontes (2012) é a reorientação dos mecanismos institucionais, que estão mais abertos e descentralizados. Nesse sentido as políticas públicas e gestão pública se direcionam para o local, invocando a participação popular e afirmação indenitária, o que de certa forma rompe com o Estado nacional centralizado e estruturado burocraticamente.

\section{Nova gestão pública e accountability social}

O modelo gerencial no Brasil foi influenciado pelo movimento da Nova Administração Pública (NAP) de origem americana e da Nova Gestão Pública (NGP) do modelo britânico. Após diversas reformas, sendo uma das mais relevantes a Reforma Gerencial do Estado Brasileiro da década de 90, num contexto de globalização econômica e aumento do desenvolvimento da tecnologia, o Estado muda para posição de promotor e regulador do desenvolvimento econômico e social ao invés de responsável direto, diversos serviços públicos passaram a ser realizados pelo terceiro setor e iniciativa privada (RIBEIRO et al., 2013).

As mudanças na administração inseridas no período de transformação social e inovação tecnológica, requerem que a gestão também se modifique. A Nova Gestão Pública (NGP) na opinião de Scaff et al. (2018) mostrou-se como uma alternativa a administração do estado. Em oposição à antiga, burocrática, cara e ineficiente administração pública a Nova Gestão Pública (NGP) é indicada como referência de governabilidade do Estado, tem como princípios novas formas de relação entre Estado, mercado e sociedade civil.

Nesse processo de mudança, na governança pública mecanismos foram desenvolvidos a fim de criar uma relação mais harmoniosa entre o governo e a sociedade. E a partir da tecnologia foi implantado no Brasil o governo eletrônico (e-gov) com importante papel em relação a transformação social e promotor da Cidadania e desenvolvimento (CAMILO et al., 2018).

No que se refere ao Governo Eletrônico, Koupak (2017) afirma que a Administração Pública vista como ineficiente e caracterizada por procedimentos burocráticos e avessa à participação da sociedade em seu funcionamento, a partir do uso da tecnologia da informação surge uma ferramenta possível ao avanço e modernização da máquina pública, pois com sua implantação as políticas públicas implementadas pelo Governo poderão se aproximar do cidadão e deixá-lo a par de toda a ação governamental.

Neste sentido o Decreto no 8.638/2016, define governança digital como a utilização, pelo setor público, de tecnologias da informação e comunicação com o objetivo de melhorar a informação e a prestação 
de serviços, incentivando a participação dos cidadãos no processo de tomada de decisão e tornando o governo mais responsável, transparente e eficaz (BRASIL, 2016).

De acordo com Camilo et al. (2018) a gestão pública através da tecnologia da informação tem possibilitado o conhecimento de dados abertos, o que pode ampliar a inclusão e o controle social. Deste modo, na opinião de Akutsu et al. (2002) a internet ao possibilitar o acesso as informações disponibilizadas pelos órgãos do governo a qualquer hora e local do mundo, pode ser um dos instrumentos mais efetivos para fortalecimento da democracia.

Os mecanismos de controle direto dos cidadãos, funcionam em poucas democracias, em geral nos países europeus onde as instituições democráticas são altamente consolidadas, nestes as condições básicas para o controle social são efetivas. Nas democracias latino-americanas esse controle é deficiente, apesar de existirem as eleições, accountability vertical, mas não são um instrumento eficaz de controle popular, pois ao invés de serem representativa são delegativas (PRZEWORSKI, 2001).

No caso brasileiro Akutsu et al. (2002) dizem que a democracia delegativa e o patrimonialismo estão em processo lento de superação, estando ligados a questão da accountability. Esses autores ao considerarem essa base patrimonialista, questionam se quem está no poder tem interesse em prestar contas através da disponibilização de informações para sociedade. Assim Araújo (2001) diz que as funções de fiscalização e controle interno e externo devem ser inseridas no contexto de ampliação dos espaços democráticos, e indicam a necessidade de repensar a accountability a fim de adotar novos mecanismos de controle que facilitem a accountability e a consolidação da democracia.

Numa sociedade com accountability plena, os gestores públicos devem prestar contas de suas ações, publicizar as decisões e ações de governo que sejam de interesse da coletividade, como exemplos: os balanços orçamentários, publicidade das licitações, com indicação de fornecedores e preços das propostas vencedoras, bem como indicação dos serviços e programas de governo oferecidos (AKUTSU et al., 2002).

A redução do déficit de informação ao cidadão é uma condição essencial para o exercício da accountability, o processo de comunicação com o cidadão mudou consideravelmente com a expansão da rede mundial de computadores através do uso da internet. No Brasil por meio de recomendação legal a internet deve ser utilizada para divulgar atos da administração pública (RESCH et al., 2017).

A necessidade de fortalecimento da democracia através do controle social e as mudanças na gestão pública decorrentes da tecnologia da informação e comunicação, podem ser viabilizadas através dos novos instrumentos de acesso as informações públicas, como o portal da transparência, obrigatório em todos os níveis de governo, disponibilizando informações que podem ser acessadas por todos os cidadãos.

\section{Portal da transparência}

O Portal da Transparência é um site de acesso livre, através do qual o cidadão pode encontrar informações sobre a gestão pública, e também se informar sobre como o dinheiro público é utilizado. Sua criação visa atender a demanda de informações relativas à gestão pública e cumprir os dispositivos estabelecidos pela Lei da transparência, que é a Lei Complementar no 131/2009, a qual estabelece normas 
de finanças públicas voltadas para a responsabilidade na gestão fiscal e dá outras providências, a fim de determinar a disponibilização, em tempo real, de informações pormenorizadas sobre a execução orçamentária e financeira da União, dos Estados, do Distrito Federal e dos Municípios. Os dados apresentados devem estar atualizados, correspondendo ao dia útil anterior.

Outro dispositivo importante para transparência da gestão pública é a Lei de acesso à informação (LAI no 12.527/2011) que dispõe sobre os procedimentos a serem observados pela União, Estados, Distrito Federal e Municípios, com o fim de garantir o acesso a informações previsto no inciso XXXIII do art. 5o , no inciso II do § 30 do art. 37 e no $\S 20$ do art. 216 da Constituição Federal. Para Michener et al. (2018) após implementar essa lei o Estado passou de detentor para guardião de informação públicas, consideram que as bases desta lei são amplas e profundas, abrangem todos os níveis de governo, poderes e entidades que administram o dinheiro público.

Na opinião de Camilo et al. (2018) a política de informação e a lei de acesso à informação surgem como oportunidades para o cidadão participar nos processos de tomada de decisão, vistoriar ações e omissões do ente governamental em todos os níveis, no monitoramento e combate à corrupção. Nessa perspectiva Almeida (2013) diz que a disponibilização eletrônica de todas as informações públicas retira do agente público a prerrogativa de decidir muitas vezes de forma arbitrária sobre a liberação das informações reduzindo assim a possibilidade de corrupção.

Para Michener et al. (2018) "frequentemente, no entanto, nem a legitimidade simbólica, nem o monitoramento, nem as preocupações competitivas resultam em compromissos com a transparência no Brasil. Políticos estaduais e municipais majoritariamente valorizam a opacidade em detrimento da transparência". Entretanto, uma maneira de combater essa opacidade é através dos instrumentos legais que permitem a fiscalização das contas públicas nos portais dos governos. Nesse sentido o portal da transparência é uma ferramenta que permite ao cidadão exercer o controle social, pois através desse portal deve ser possibilitado a qualquer pessoa verificar a aplicação dos recursos públicos.

A Lei da Transparência (LC 131/2009) estabelece em seu artigo 48, que os entes da Federação disponibilizarão a qualquer pessoa física ou jurídica o acesso a informações referentes a: “I - quanto à despesa: todos os atos praticados pelas unidades gestoras no decorrer da execução da despesa, no momento de sua realização, com a disponibilização mínima dos dados referentes ao número do correspondente processo, ao bem fornecido ou ao serviço prestado, à pessoa física ou jurídica beneficiária do pagamento e, quando for o caso, ao procedimento licitatório realizado;" e no inciso II - quanto à receita: "o lançamento e o recebimento de toda a receita das unidades gestoras, inclusive referente a recursos extraordinários." Também sobre as receitas a Lei de acesso à informação no 12.527/2011 no art.8ㅇ § "1ㅇ Na divulgação das informações a que se refere o caput, deverão constar, no mínimo: Il - registros de quaisquer repasses ou transferências de recursos financeiros" (BRASIL, 2011).

Estes dispositivos legais tornam possível aos órgãos de controle realizar accountability horizontal como também aos cidadãos fiscalizarem as contas públicas. Assim para uma efetiva fiscalização deve ser 
possibilitado ao cidadão compreender as contas públicas, de onde vem e para onde vai o dinheiro arrecadado que integram as receitas, a fim de custear as despesas e necessidades de investimentos públicos.

\section{Composição das receitas municipais}

A partir da reforma de 1967 na opinião de Rezende (2012) houve uma concentração das competências tributárias da União, como também houve uma inovação no mecanismo de transferências intergovernamentais de receitas, que passou a beneficiar sobretudo os Estados menos desenvolvidos e os municípios menos populosos.

As receitas orçamentárias podem ser classificadas a partir da captação dos recursos, da origem dos recursos ou do orçamento a que estão vinculadas. Do ponto de vista da captação, as receitas podem ser classificadas como próprias que são as arrecadadas pelas próprias entidades encarregadas pela sua aplicação ou de transferências que são as receitas provenientes do repasse de recursos captados por outras instituições (REZENDE, 2012). São exemplos de receitas de transferências as que são repassadas pela União para os Fundos de participação dos Estados e Municípios.

Os governos locais conforme Passos et al. (2018) são responsáveis pela "cobrança do Imposto sobre Serviços de Qualquer Natureza (ISSQN); o Imposto Predial e Territorial Urbano (IPTU); e o Imposto sobre Transmissão 'intervivos' de bens imóveis (ITBI)". Esses encargos tributários são destinados para constituir a receita pública, como descrito por Passos et al. (2018) "Correspondem aos valores de recursos que entram nas contas e subcontas de Receita que serão utilizados para o funcionamento da máquina administrativa, da coisa pública, atendimento da demanda da sociedade, assim como para investimentos, pagamento de dívidas e outras despesas".

A receita disponível vai depender do quanto cada esfera repassa e recebe das outras. No caso da União, a receita disponível é menor do que a receita bruta, pois há transferências de recursos para os demais entes da federação. No caso dos municípios o balanço da receita é inverso, principalmente, no caso dos municípios menos desenvolvidos e de pequeno porte, os quais recebem transferências tanto da União como dos Estados (GIAMBIAGI, 2011).

Essas transferências buscam corrigir o desequilíbrio fiscal da federação e representam uma oportunidade de diminuir as disparidades regionais, a fim de uma equidade entre os governos que apresentam capacidades de arrecadação distintas, no intuito de atender as demandas da população e seus respectivos gastos de atendimentos (BAIÃO et al., 2014). Desse modo a composição dessas receitas destinase ao atendimento de serviços como os da área da saúde e outros serviços essenciais à população.

\section{Sistema Único de Saúde (SUS) - Breve cenário}

A consolidação da saúde como direito social, está determinada através dos art. 196 ao art. 200 da Constituição Federal de 1988, foi então criado o Sistema Único de Saúde (SUS). O conceito de saúde foi ampliado como também ficou estabelecido a participação da comunidade no SUS. Em continuidade ao processo de construção do SUS como Política Pública, foram regulamentadas as Leis Orgânicas da Saúde 
(LOS) que são as Leis 8.080/90 e Lei 8.142/90, definindo pontos importantes como os princípios que regem o SUS e estabelecem mecanismos de participação popular. A partir dessas legislações houve um grande avanço na implantação e consolidação dessa Política Pública.

O SUS tornou-se uma rede ampla que integra tantas ações quanto os serviços de saúde, desde procedimentos simples como verificação da pressão arterial até os mais complexos como transplante de órgãos. Com o dever de garantir acesso integral, universal e gratuito para todos brasileiros, desde a atenção primária a média e alta complexidades, os serviços urgência e emergência, a atenção hospitalar, as ações e serviços das vigilâncias epidemiológica, sanitária e ambiental e assistência farmacêutica (BRASIL, 2020).

A atenção integral à saúde é direito de todos brasileiros, no entanto o cenário de assistência à saúde no SUS no Brasil ainda é uma área que apresenta superlotação dos hospitais públicos, onde muitos brasileiros esperam nas filas, seja por uma consulta, um exame diagnóstico ou uma cirurgia eletiva. A insuficiência no número de leitos impõe aos pacientes, muitas vezes, a passarem dias acomodados em cadeiras ou em macas, nos corredores dos hospitais à espera de um leito de enfermaria ou de UTI.

A necessidade de ampliação da quantidade de leitos, exames, equipamentos, profissionais e demais recursos para atendimento foi intensificada quando surgiu a COVID-19, uma doença respiratória aguda causada pelo novo coronavírus, que pode provocar uma síndrome respiratória aguda grave. Essa doença se disseminou rapidamente, e logo tornou-se uma pandemia global. Ocorreu um aumento drástico no número de casos, e como consequência uma elevada demanda pelos serviços de assistência médico-hospitalar, principalmente nos níveis de alta complexidade referente a disponibilidade de leitos de UTI, para os pacientes que desenvolvem a forma grave da COVID-19 e necessitam de ventilação mecânica.

A situação logo caracterizou-se como emergência de saúde pública, tornando urgente a abertura de novos leitos hospitalares, para isso foi necessário a aquisição de respiradores, ventiladores pulmonares, máscaras e dentre outros insumos destinados ao atendimento de pacientes em situações graves, bem como equipamentos de proteção individual - EPIs para os profissionais da saúde.

Para atender essa elevada demanda, a administração pública brasileira criou a Lei № 13.979/2020, conhecida como "Lei Coronavírus" que dispõe, entre outras medidas, no Art. 4o "Fica dispensada a licitação para aquisição de bens, serviços e insumos de saúde destinados ao enfrentamento da emergência de saúde pública". Ainda no Art. 4 §2 que todas as contratações ou aquisições, amparadas nesta Lei devem ser imediatamente disponibilizadas em sítio oficial específico na rede mundial de computadores (internet), contendo também as informações previstas no § 3ㅇ do art. 8ㅇda Lei ํo 12.527/2011.

Neste sentido, os dispositivos legais são imprescindíveis para o fortalecimento democrático e consolidação do SUS, funcionam como instrumentos que viabilizam a participação popular e o controle social através das TICs com o uso da internet. De acordo com Akutsu et al. (2002) "O conceito de accountability envolve duas partes: a primeira delega responsabilidade para que a segunda proceda à gestão dos recursos: ao mesmo tempo, gera a obrigação daquele que administra os recursos de prestar contas de sua gestão, demonstrando o bom uso desses recursos". Deste modo ao delegar ao gestor público a responsabilidade pelo investimento dos recursos públicos, como no caso da política pública de saúde no Brasil, em 
contrapartida o cidadão-usuário deve ter a prestação de contas de todos os recursos públicos.

\section{METODOLOGIA}

Este estudo buscou avaliar se as informações dos portais da transparência de 32 municípios pernambucanos estão em conformidade com a lei da transparência (LC 131/2009), no que se refere a disponibilização de informações nos portais da transparência relativas a Transferências e Receitas de recursos financeiros do Sistema Único de Saúde-SUS para o enfrentamento ao coronavírus COVID-19, nesses municípios pernambucanos.

Foi realizada uma pesquisa bibliográfica com levantamento de estudos relacionados ao assunto, publicados em sites científicos. E coleta de dados secundários, de acordo com O'Leary (2019) se tratam de dados situacionais e podem ser encontrados em documentos, bases de dados e na internet, são dados existentes que frequentemente são encontrados na internet, mas não dependem dela para existir. Nesta pesquisa selecionamos os dados disponibilizados na internet através dos portais da transparência do Fundo Nacional de Saúde-FNS e portais da transparência das prefeituras dos municípios selecionados.

A abordagem, desta pesquisa é considerada como quali-quantitativa, ou seja, aborda tanto questões que se caracterizam na pesquisa qualitativa como na quantitativa. Martins (2004) considera que, se há uma característica que constitui a marca dos métodos qualitativos, é a flexibilidade, principalmente quanto às técnicas de coleta de dados, incorporando aquelas mais adequadas à observação que está sendo feita. Conforme Fonseca (2002) a análise quantitativa tem um embasamento a partir de dados estatísticos, que podem ser tabelados, classificados conforme a necessidade do pesquisador.

$\mathrm{Na}$ escolha dos municípios pernambucanos para coleta dos dados nos portais da transparência, consideramos a quantidade de municípios 185 e a extensão territorial do estado de Pernambuco 98.067,881 $\mathrm{km}^{2}$. A partir desse contexto optamos por selecionar uma amostra de 08 municípios de cada uma das quatro regiões geográficas intermediárias, essas regiões de acordo com o IBGE (2017) organizam o território, articulando Regiões Geográficas Imediatas por meio de um polo de hierarquia superior diferenciado a partir dos fluxos de gestão privado e público e da existência de funções urbanas de maior complexidade. Essa regionalização do território brasileiro foi baseada na identificação de cidades-polo e dos municípios a elas vinculados.

No Estado de Pernambuco existem quatro Regiões geográficas imediatas, nas quais as cidades-polos de hierarquia são representadas pelas cidades de Recife, Caruaru, Serra Talhada e Petrolina. (IBGE, 2017). Essas 04 (quatro) cidades-polo foram selecionadas e incluídos mais 07 (sete) municípios a elas vinculados por suas respectivas Regiões Geográficas Imediatas, totalizando 32 municípios pernambucanos.

A coleta de dados nos portais da transparência foi realizada no período de 21 a 29 de setembro de 2020. Para não haver divergência de valores entre os portais do FNS e FMS, devido atualizações do sistema, a pesquisa foi realizada de forma simultânea, assim para cada página da internet referente a transferência de recurso do portal da transparência do Fundo Nacional de Saúde-FNS de determinado município, como exemplo Recife, ao mesmo era aberta outra janela da internet para o portal da transparência do Fundo 
municipal de Saúde-FMS da prefeitura de Recife, correspondendo ao município pesquisado no portal do FNS simultaneamente em mesmo dia e horário para cada busca.

Para avaliar a conformidade dos portais da transparência desses municípios com Lei da Transparência no 131/2009, foram selecionados os seguintes os dispositivos da referida lei:

Artigo $1^{\circ} \|$ - liberação ao pleno conhecimento e acompanhamento da sociedade, em tempo real, de informações pormenorizadas sobre a execução orçamentária e financeira, em meios eletrônicos de acesso público.

Artigo $2^{\circ}$ - Os entes da Federação disponibilizarão a qualquer pessoa física ou jurídica o acesso a informações referentes a: Inciso II - Quanto à receita: recebimento de toda a receita das unidades gestoras.

A partir desses critérios foram coletados e analisados os dados dos portais da transparência das referidas prefeituras e do site do Fundo Nacional de Saúde (FNS) que disponibiliza os valores de repasse de verbas da União para o SUS, na modalidade fundo a fundo, em que o dinheiro é transferido diretamente do Fundo Nacional de Saúde-FNS para o Fundo Municipal de Saúde-FMS de cada município.

\section{Análise dos dados e discussões}

Considerando que a proposta de regionalização do território brasileiro foi baseada na identificação de cidades-polo e dos municípios a elas vinculados. Identificamos no mapa correspondente a figura 1, as Regiões Geográficas intermediarias de Pernambuco, a partir desse modelo de divisão regional, foram selecionados 08 municípios de cada Região Geográfica Intermediária para que assim fosse possível incluir uma diversidade de municípios, abrangendo as diversas regiões do Estado. Para a pesquisa alcançar essa amplitude territorial, o uso da internet foi um fator primordial para que as barreiras de tempo e espaço fossem superadas através do uso das Tecnologias da informação e comunicação (TICs), possibilitando o acesso as informações disponibilizadas pelos gestores municipais, nos portais da transparência dos correspondentes municípios.

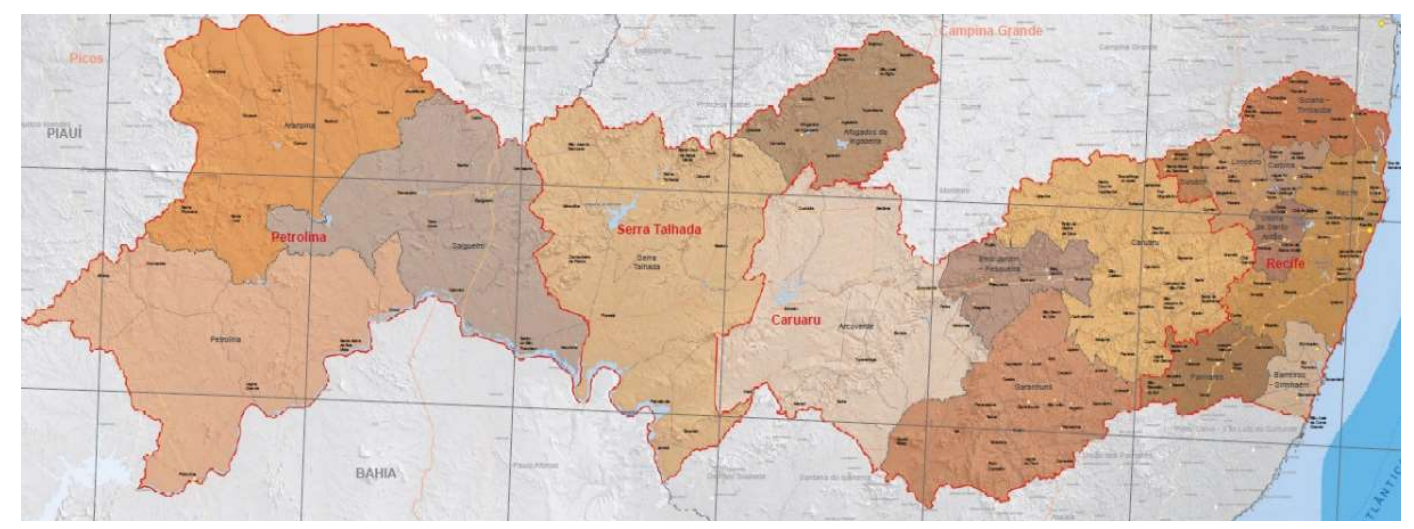

Figura 1: Mapa das Regiões Geográficas de Pernambuco.

A partir dessa contextualização, caracterizamos a amostra selecionando as cidades-polo e os municípios a elas vinculados, descrevendo a região e população em número de habitantes de cada município, com apresentado a seguir no quadro1. 
Quadro 1: Contextualização das regiões e suas populações por município.

\begin{tabular}{|l|l|l|l|}
\hline Regiões Geográficas intermediárias de Pernambuco (Cidades polo: Recife, Caruaru, Serra Talhada e Petrolina) \\
\hline Região I & Região II & Região III & Região IV \\
\hline Município - no habitantes & Município - no habitantes & Município - $\mathbf{n}$ - habitantes & Município - $\mathbf{n}$ habitantes \\
\hline Recife - 1.645.727 hab. & Caruaru -361.118 hab. & Serra Talhada -86.350 hab. & Petrolina- 349.145 hab. \\
\hline Olinda -392.482 hab. & Bezerros - 60.798 hab. & Afogados da Ingazeira- 37.259 & Araripina - 84.418 hab. \\
\hline Paulista - 331.774 hab. & Arcoverde-74.338 hab. & São José do Belmonte-33.959 & Ouricuri 69.459 hab. \\
\hline Vitória Sto Antão- 138.757 & Belo Jardim-76.439 hab. & Floresta-32.873 hab. & Salgueiro- 60.930 hab. \\
\hline Carpina 83.641 hab. & Palmares-63.250 hab. & Tabira-28.534 hab. & Sta Maria Boa Vista-41.931 \\
\hline Surubim 65.089 hab. & Bezerros -60798 hab. & Carnaíba-19.551 hab. & Exu-31.825 hab. \\
\hline Itambé 36.447 hab. & Cachoeirinha-20.380 ab. & Triunfo-15.254 hab. & Lagoa Grande-25.601 hab. \\
\hline Amaraji 22.829 hab. & Cumaru-10.906 hab. & Ingazeira-4.548 hab. & Serrita-19.165 hab. \\
\hline
\end{tabular}

A coleta de dados dos FMS dos portais da transparência dos municípios descritos na tabela 1, e coleta de dados no Portal da transparência Fundo Nacional de Saúde-FNS, foi realizada de forma simultânea, para cada página da internet referente a transferência de recurso do portal da transparência do Fundo Nacional de Saúde-FNS de determinado município, ao mesmo era aberto uma nova janela da internet para o portal da transparência da prefeitura do correspondente município pesquisado no portal do FNS. Desse modo, obtivemos os dados referentes aos valores dos recursos do Sistema Único de Saúde-SUS, destinados ao enfrentamento da pandemia do novo coronavírus COVID-19 e transferidos pelo Fundo Nacional de SaúdeFNS para Fundo Municipal de Saúde-FMS de cada município pesquisado, simultaneamente em mesmo dia e horário referente a cada busca.

Os dados disponibilizados pelo Fundo Nacional de Saúde-FNS referente aos valores dos Recursos transferidos, na modalidade fundo a fundo, da União para os municípios foram coletados e comparados com os valores dos Recursos recebidos da União pelo Fundo Municipal de Saúde-FMS e disponibilizados pelo Portal da transparência de cada prefeitura municipal selecionada nesse estudo. Diante desse processo onde um (União) envia e outro (município) recebe, foi possível fazer uma análise comparativa desses valores disponibilizados nos portais. Que foram organizados e apresentados nos Gráficos 1, 2, 3 e 4, correspondendo as quatro Regiões geográficas imediatas e os municípios a elas vinculados.

Esses gráficos apresentam os valores em reais transferidos pela União para compor as receitas municipais, provenientes do repasse de recursos captados pelo governo Federal. No caso em estudo esses recursos visam atender as demandas da população com relação a necessidades de assistência à saúde, e seus respectivos gastos no enfrentamento de emergência de saúde pública decorrente da Pandemia Covid-19.

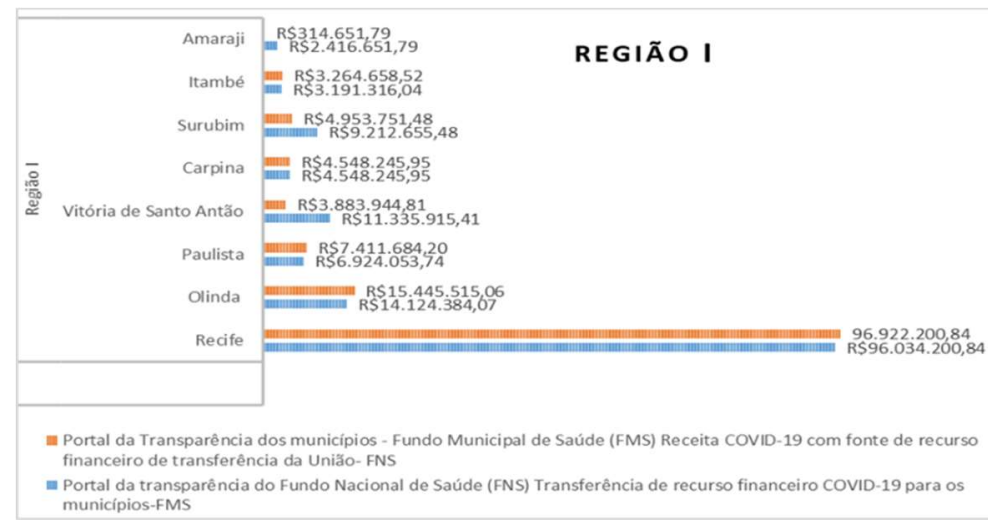

Gráfico 1: Valores em reais transferidos pela União da região 1. 
Como mostra o gráfico 01, quanto aos valores de recursos disponíveis nos portais da transparência dos municípios dessa região, dos 08 municípios pesquisados apenas um deles, que foi Carpina informou em seu portal da transparência o valor exatamente igual ao repasse que consta no portal da transparência do FNS. Os municípios de Recife e Olinda mostram valores bem aproximados, no entanto portais da transparência dessas cidades informam no FMS valores um pouco mais altos do que o FNS. Os demais municípios informaram valores dos mais aproximados, aos mais discrepantes na seguinte ordem: Itambé, Paulista, Surubim, Vitória e Amaraji, este último informa o valor mais discrepante dessa região.

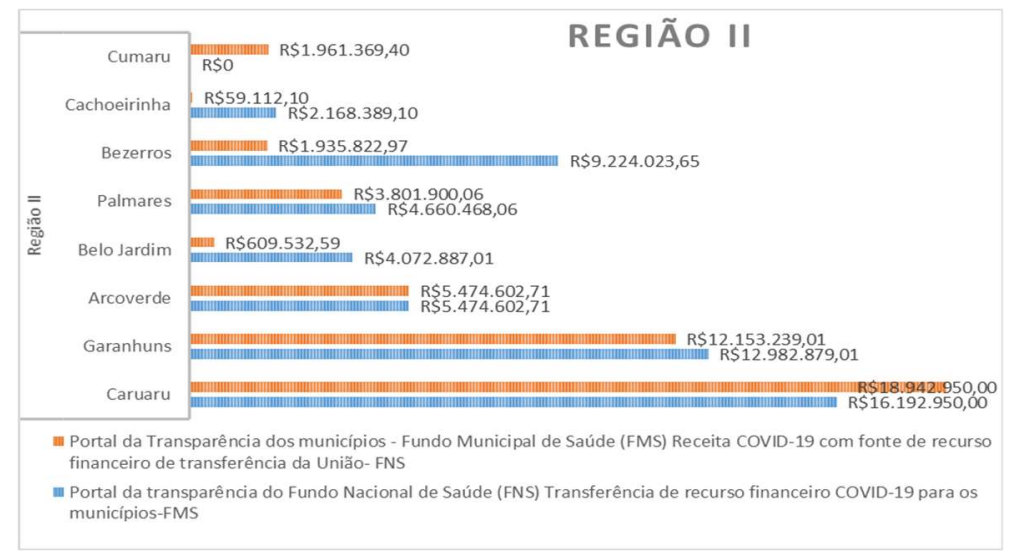

Gráfico 2: Valores em reais transferidos pela União da região 2.

Na Região geográfica imediata II, apresentada no gráfico 2, os portais da transparência dos municípios a ela vinculados também evidenciam valores desiguais entre os repasses transferidos pelo FNS e os recursos recebidos nas receitas municipais. Dos 08 municípios pesquisados, apenas Arcoverde informou em seu portal da transparência o valor exatamente igual ao repasse que consta no portal da transparência do FNS. No caso de Garanhuns é apresentado uma diferença mínima entre esses valores, sendo menor do que o do portal do FNS. Enquanto o município de Caruaru mostra valor aproximado, no entanto portal da transparência dessa cidade informa no FMS valor mais alto do que o FNS. Os outros 04 (quatro) municípios dessa região apresentam valores bem menores quando comparados aos valores repassados pelo FNS. E o portal do Munícipio de Cumaru não consta recebimento de transferência do FNS para enfrentamento a COVID-19, embora conste o repasse de recurso no portal do FNS.

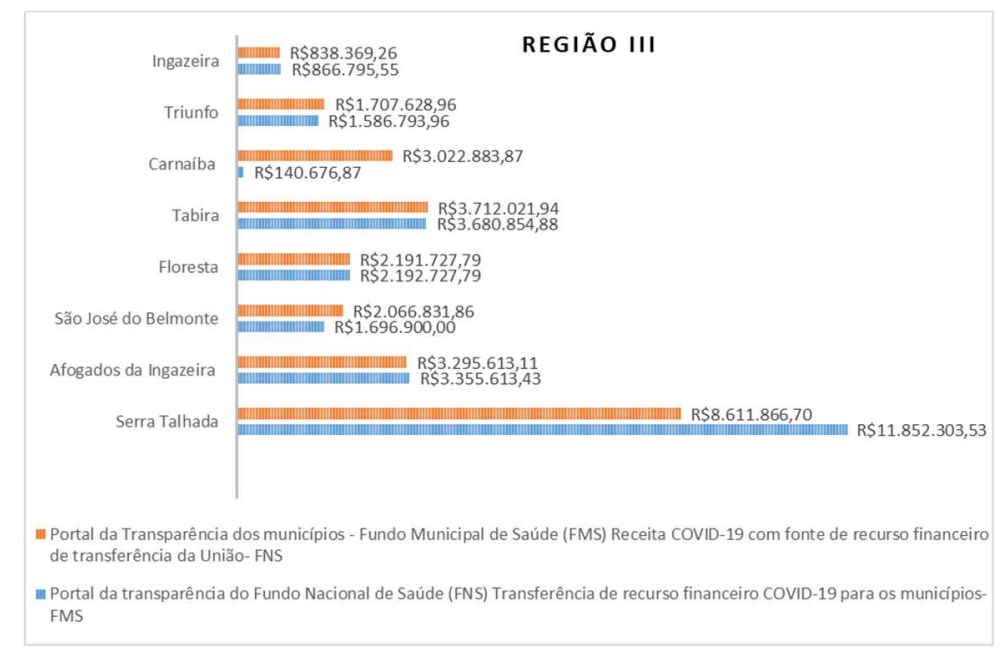

Gráfico 3: Valores em reais transferidos pela União da região 3. 
A análise do gráfico 3, referente a Região geográfica imediata III, é possível constatar que os municípios: Floresta, Ingazeira, Tabira, Afogados da Ingazeira e Triunfo apresentam em seus portais da transparência os valores dos recursos recebidos de transferências da União, relativamente idênticos aos dos repasses para os municípios constantes no portal da transparência do FNS. Também na região encontramos um município São José do Belmonte que informa valor aproximado, no entanto o portal da transparência dessa cidade informa no FMS valor um pouco mais elevado do que o portal do FNS. Os outros portais municipais de Serra Talhada e Carnaíba apresentam divergência entre os valores transferidos pelo FNS e os Recebidos dessas transferências nos FMS. Sendo o portal de Carnaíba o mais divergente. No entanto essa região III revelou maior quantitativo de portais da transparência que informam no FMS valores dos recursos mais próximos aos que são transferidos pelo FNS para estes municípios.

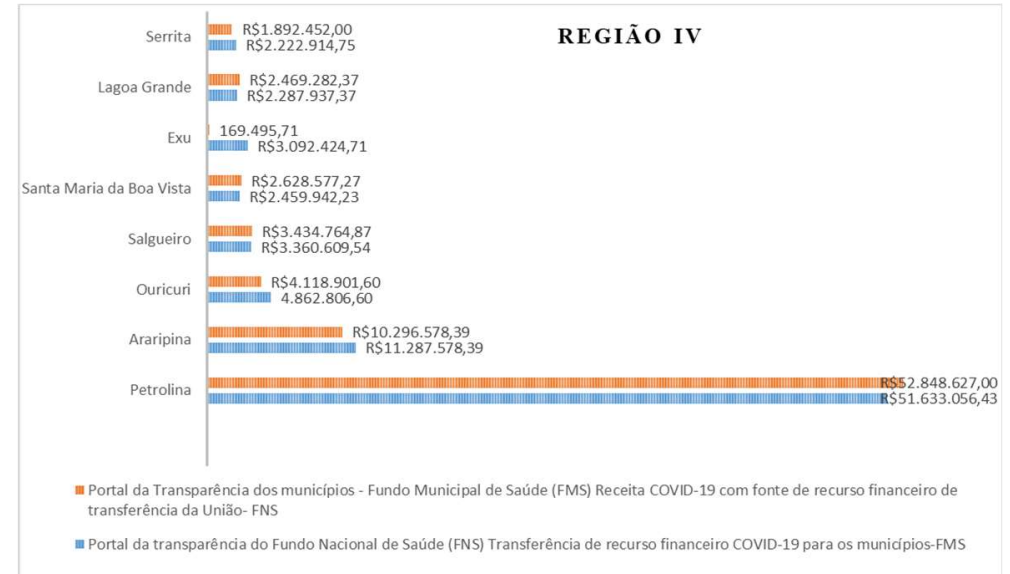

Gráfico 4: Valores em reais transferidos pela União da região 4.

Diante os dados apresentados no gráfico 04 demonstra que a maioria dos municípios da região IV, apresentam valores equivalentes de recursos nos portais da transparência dos municípios, quando comparados aos valores de transferências de recursos da União- FNS para estes municípios. Os portais da transparência dos sete municípios: Petrolina, Araripina, Ouricuri, Salgueiro, Santa Maria da Boa Vista, Lagoa Grande e Serrita demonstram mínima diferença nas informações referentes aos recursos transferidos pelo FNS e recebidos pelos FMS. Apenas um portal da transparência municipal-FMS, o de Exu apresentou informações inconsistentes com os dados referentes as transferências realizadas pelo FNS.

Durante a coleta de dados dessa pesquisa também constatamos que todos os portais da transparência dos municípios disponibilizaram um portal exclusivo para transparência Covid-19, e o portal da transparência do Fundo Nacional de Saúde-FNS oferece as informações de forma detalhada sobre as transferências realizadas, disponibilizando separadamente as transferências relativas ao coronavírus (COIVID-19), o que possibilita realizar a coleta de dados de forma mais precisa e confrontar com as informações de recebimento desses recursos nos portais da transparência dos municípios .

A análise dos dados dessa pesquisa, possibilitou avaliar que a maioria dos portais da transparência dos municípios selecionados na amostra estão em conformidade com Lei da Transparência no 131/2009, com relação ao seguinte dispositivos da referida lei: Artigo $2^{\circ}$ - Os entes da Federação disponibilizarão a qualquer 
pessoa física ou jurídica o acesso a informações referentes a: Inciso II - Quanto à receita: recebimento de toda a receita das unidades gestoras (BRASIL, 2009).

No entanto dos 32 municípios pesquisados 10 informaram valores de recebimento das transferências com elevada discrepância quando confrontadas com as informações dos recursos enviados e informados no portal do Fundo Nacional de Saúde-FNS, portanto não estão disponibilizando o recebimento de toda a receita das unidades gestoras. Ainda um município que não informou recebimento de transferência de recursos Covid-19 do FNS. Com base nesses dados podemos constatar que esses 11 municípios também não estão em conformidade Lei da Transparência no 131/2009 em seu artigo $1^{\circ}$ II - "liberação ao pleno conhecimento e acompanhamento da sociedade, em tempo real, de informações pormenorizadas sobre a execução orçamentária e financeira, em meios eletrônicos de acesso público" (BRASIL, 2009).

Visto que as informações disponibilizadas nesses 11 portais municipais apresentam discrepância de valores ou indisponibilidade da informação, infere-se que a sociedade não terá o pleno conhecimento e acompanhamento de informações pormenorizadas sobre a execução orçamentária e financeira, em meios eletrônicos de acesso público, como recomenda a Lei da Transparência (LC 131/2009) (BRASIL, 2009).

Dentre os municípios selecionados para pesquisa, das quatro Regiões Geográficas intermediarias de Pernambuco, os resultados demonstraram que os portais dos municípios da Região IV, apresentam o maior quantitativo de municípios com valores equivalentes de recursos para enfrentamento covid-19 nos portais da transparência dos municípios- FMS, quando comparados aos valores de transferências de recursos da União- FNS para estes municípios.

A região II, no entanto, revelou o maior quantitativo de municípios com valores mais discrepantes, em seus portais da transparência. 04 (quatro) municípios dessa região apresentam valores bem menores de recebimento das transferências relativas ao Covid-19, quando comparados aos valores repassados pelo FNS para os FMS desses municípios. Ainda o portal do Munícipio de Cumaru não consta recebimento de transferência do FNS para enfrentamento a COVID-19, embora conste o repasse de recurso no portal do FNS.

Esses resultados indicam que muitos gestores públicos municipais ainda precisam desempenhar melhor a responsabilização e prestação de contas para a sociedade, favorecendo o controle social através das Tecnologias da informação e comunicação (TICS) e do uso através da internet disponibilizar o conhecimento de dados abertos, para uma efetiva transparência, elemento essencial da accountability na administração pública. Neste sentido a informação desempenha um papel fundamental e o uso da internet surge como instrumento capaz de viabilizar a participação cidadã.

Outra característica que ficou evidenciada a partir dessa pesquisa foi a possibilidade de qualquer pessoa fiscalizar as contas públicas, pois as informações e dados execução orçamentária e financeira devem estar disponíveis em meios eletrônicos de acesso público. Nessa sociedade atual a produção e compartilhamento de informações, ocorrem numa interligação que independe da localização espaçotemporal das pessoas, como foi possível constatar que mesmo diante a grande extensão territorial do Estado de Pernambuco, através das TICs e o uso da internet foi viabilizado o acesso a prestação de contas dos 
gestores municipais das quatro Regiões Geográficas intermediarias, independente da distância geográfica em que se encontravam os municípios, superando as barreiras de tempo e espaço.

Assim essas novas configurações exigem governos mais transparentes a fim de atender as demandas da sociedade, como no caso de assistência à saúde através do SUS, os recursos direcionados a esta política Pública devem ser disponibilizadas para que a sociedade o pleno conhecimento e acompanhamento de informações, em meios eletrônicos de acesso público como recomenda a Lei da Transparência (LC 131/2009).

\section{CONCLUSÕES}

As tecnologias da informação e comunicação - TICs, com o uso da internet tem transformado as relações sociais e desenvolvimento da sociedade, transformando os cenários mundiais, as barreiras de tempo e espaço da comunicação humana foram superadas. Essas mudanças refletem na gestão pública mudando a relação entre governo, Estado e sociedade. Sendo necessárias novas formas de pensar a gestão e a participação. A administração pública não pode ficar alheia as novas configurações.

E os gestores devem fornecer a disponibilidade de informações pelos órgãos governamentais, com o uso das tecnologias da informação e comunicação - TICs, através da internet, sem restrição de informação, tempo ou localização, possibilitando que a accountability horizontal seja efetiva, fortalecendo a democracia brasileira.

Surge a necessidade dos governos desenvolverem novas competências, no intuito de atender as demandas da sociedade e desenvolver uma gestão mais eficiente e transparente e alcance da efetividade das políticas públicas. Como no caso Sistema Único de Saúde- SUS, que já precisava de melhorias, com a pandemia Covid-19, essa demanda foi intensificada, diante a necessidade de ampliação da assistência à saúde, aumento quantidade de leitos, exames, equipamentos, profissionais e demais recursos para atendimento à saúde da população.

Entre as atribuições necessárias a gestão pública, ergue-se a necessidade dos gestores públicos desenvolverem uma gestão participativa, descentralizada e utilizar a internet para disponibilizar de forma aberta os dados de sua gestão. Sendo indispensável informar como e onde estão sendo aplicados os recursos públicos, conforme exige a legislação brasileira, lei da transparência no 131/2009.

Diante deste contexto, a pesquisa avaliou se as informações dos portais da transparência das gestões municipais em conformidade com a lei da transparência $n$ ำ131/2009, no que se refere aos recursos do SUS repassadas aos Fundos Municipais de Saúde, para o enfrentamento da COVID-19.

Como limitação o estudo apresentou apenas a análise das transferências e receitas para COVID-19. Como sugestão para pesquisas posteriores indica-se a análise das informações quanto à despesa, com a disponibilização mínima dos dados referentes ao número do correspondente processo, ao bem fornecido ou ao serviço prestado durante a pandemia Covid-19, observando os dispositivos da Lei № 13.979/2020, conhecida como "Lei Coronavírus". 


\section{REFERÊNCIAS}

AKUTSU, L.; PINHO, J. A. G.. Sociedade da informação, accountability e democracia delegativa: investigação em portais de governo no Brasil. RAP, Rio de Janeiro, v.36, n.5, p.723-745, 2002

ARAÚJO, A. N.. Articulação entre o conceito de governança e as funções de planejamento e controle na gestão de políticas públicas. In: CONGRESSO CONSAD DE GESTÃO PÚBLICA, 3. Anais. Brasília, 2010.

BAIÃO, A. L.; CUNHA, A. S.; SOUZA, F. S. R.. O Papel das transferências intergovernamentais na equalização fiscal dos municípios brasileiros. Revista do Serviço Público, v.68, n.3, p.583-610, 2014.

BALBE, R.. Uso de tecnologias de informação e comunicação na gestão pública: exemplos no governo federal. Revista do Serviço Público, v.61, n.2, p.189-209, 2014. DOI: https://doi.org/10.21874/rsp.v61i2.45

BRASIL. Decreto n. 8.638 de 15, de janeiro de 2016. Institui a Política de Governança Digital no âmbito dos órgãos e das entidades da administração pública federal direta, autárquica e fundacional. Brasília: DOU, 2016.

BRASIL. Lei complementar n. 131/2009. Estabelece normas de finanças públicas voltadas para a responsabilidade na gestão fiscal e dá outras providências. Brasília: DOU, 2009.

BRASIL. Lei n. 12.527, de 18 de novembro de 2011. Regula o acesso a informações. Brasília: DOU, 2011.

BRASIL. Ministério da Saúde. Sistema Único de Saúde (SUS): estrutura, princípios e como funciona. Brasília: MS, 2020.

CAMILO, S. O.; MANENTI, R. V.; YAMAGUCHI, C. K.. Práticas de governança pública municipal: análise informacional dos sítios eletrônicos em portais de transparência. Revista de Ciências da Administração, Santa Catarina, v.1, n.2, p.8-23, 2018.

CASTELLS, M.. A sociedade em rede. In: VENÂNCIO, R.. A era da informação: economia, sociedade e cultural. São Paulo: Paz e Terra, 1999.

FONSECA, J. J. S.. Metodologia da pesquisa científica. Fortaleza: UEC, 2002.

FRANCO, Â. H.; CARVALHO, Â. M.; SANTOS, P. L.. Políticas públicas de informação e Inteligência Coletiva: os desafios e as possibilidades para a democratização da informação. Informação \& Sociedade, v.29, n.1, 2019.

GIAMBIAGI, F.. Finanças públicas: teoria e prática no Brasil. 4 ed. Rio de Janeiro: Elsevier, 2011.
GIL, A. C.. Como elaborar projetos de pesquisa. 5 ed. São Paulo: Atlas, 2010.

FONTES, B. A.. Redes sociais e poder local. Recife: EDUFPE, 2012.

IVAR, A. M.. A Sociedade-rede e o estado-rede. São Paulo: Revistas eletrônicas FMU, 2014.

KOUPAK, K.. Governo eletrônico: Possibilidades e desafios. Congresso de Administração da América Latina. Ponta Grossa, 2017.

MARTINS, M. H. H. T.. Metodologia qualitativa de pesquisa. Revista Universidade de São Paulo Educação e Pesquisa, v.30, n.2, p.289-300., 2004.

MICHENER, G.; CONTRERAS, E.; NISKIER, I.. Da opacidade à transparência?. Avaliando a Lei de Acesso à Informação no Brasil cinco anos depois. Revista de Administração Pública, v.52, n.4, p.610-629, 2018. DOI:

https://dx.doi.org/10.1590/0034-761220170289

O'LEARY, Z.. Como fazer seu projeto de pesquisa: guia prático. Petrópolis: Vozes, 2019.

PASSOS, C. R.; Nascimento, J. C.. Fundo de participação dos municípios na composição das receitas: um estudo sobre dependência dos municípios piauienses nos anos 2013 a 2016. 4 ed. Vitória, 2018.

PRZEWORSKI, A.. Ama a incerteza e serás democrático. Novos Estudos, n.9, p.36-46, 2001.

ROVER, A. J.; SANTOS, P. M.; FERREIRA, M. V. A.; BERNARDES, M. B.; PINTO, C. A. D.; YAMAOKA, E. J.; JÚNIOR, E. S.. Avaliação de portais e sítios governamentais no Brasil. In: ROVER, A. J.; GALINDO, F.. O Governo Eletrônico e suas múltiplas facetas. Zaragoza: Lefis Series, 2010. p.11-38.

RESCH, S.; SANTOS, I. S.; SCHURGELIES, V.. Accountability: estudo da transparência do portal da Finep. 2017.

REZENDE, F.. Finanças Públicas. 2 ed. São Paulo: Atlas, 2012.

RIBEIRO, L. M. P.; PEREIRA, J. R.; BENEDICTO, G. C.. As reformas da administração pública brasileira: uma contextualização do seu cenário, dos entraves e das novas perspectivas, 2013.

SCAFF, E.; SOUZA, K.; PAXE, I.. Implications of the New Public Management in education: Comparative analysis between Brazil and Angola. Education Policy Analysis Archives, v.26, n.129. 2018. DOI: https://doi.org/10.14507/epaa.26.3602

A CBPC - Companhia Brasileira de Produção Científica (CNPJ: 11.221.422/0001-03) detém os direitos materiais desta publicação. Os direitos referem-se à publicação do trabalho em qualquer parte do mundo, incluindo os direitos às renovações, expansões e disseminações da contribuição, bem como outros direitos subsidiários. Todos os trabalhos publicados eletronicamente poderão posteriormente ser publicados em coletâneas impressas sob coordenação da Sapientiae Publishing, da Companhia Brasileira de Produção Científica e seus parceiros autorizados. Os (as) autores (as) preservam os direitos autorais, mas não têm permissão para a publicação da contribuição em outro meio, impresso ou digital, em português ou em tradução. 